\title{
PENINGKATAN KINERJA GURU MELALUI MUSYAWARAH GURU MATA PELAJARAN ( MGMP ) BAHASA INDONESIA DI SMPN 1 LABUHAN HAJI TAHUN 2016/2017
}

\author{
Islahuddin \\ SMPN 1 Selong \\ Posel: islahuddin17@gmail.com.
}

\begin{abstract}
The purpose of this study was to improve the performance of Indonesian language teachers in (1) learning planning, (2) the application of learning strategies, (3) classroom practice, and the implementation of MGMP learning (Subject Teacher Consultation) at Labuhan Haji 1 Junior High School in East Lombok Regency. The approach used is a quantitative approach to the type of action. The object of this study were 15 Indonesian Language teachers, 15 Indonesian Language teachers who were members of the Central Rayon Indonesian Language MGMP whose activities were centered at Labuhan Haji 1 Junior High School in East Lombok Regency. The data instruments used were knowledge tests, analysis, interviews, and portfolios. Hypothesis testing is done by looking at the improvement in the performance of the teacher's curriculum. The average score of the work score increased from 53.2 to reach 68.9 in cycle II. Because the performance score has reached 68.9 (rounded to 70), the alternative Hypothesis ( $\mathrm{Ha}$ ) which states the implementation of MGMP at Labuhan Haji 1 Public Middle School can improve teacher performance in learning planning, classroom management, and learning evaluation. The results of this study are that the implementation of MGMP in Labuhan Haji Middle School 1 can improve the performance of Indonesian Language teachers in learning planning, implementation of learning strategies, and learning. Thus the MGMP provisions that succeed in implementing the principles of human price management can improve the performance of Indonesian Language teachers in learning. Therefore, education teachers, school principals, and education supervisors are empowering the MGMP MGMP that exists mainly in schools because it can improve teacher professionalism.
\end{abstract}

Keywords: teacher performance; MGMP; Indonesian language.

\begin{abstract}
Abstrak
Tujuan penelitian ini adalah untuk meningkatkan kinerja guru Bahasa Indonesia dalam (1) merencanakan pembelajaran, (2) menerapkan strategi pembelajaran, (3) mengelola kelas, dan mengevaluasi pembelajaran melalui pelaksanaan MGMP ( Musyawarah Guru Mata Pelajaran ) di SMPN 1 Labuhan Haji Kabupaten Lombok Timur. Pendekatan yang digunakan adalah pendekatan kuantitatif dengan jenis penelitian tindakan dengan dua siklus. Obyek penelitian ini adalah 15 guru Bahasa Indonesia 15 guru Bahasa Indonesia yang menjadi anggota MGMP Bahasa Indonesia Rayon Tengah yang kegiatannya dipusatkan di SMPN 1 Labuhan Haji Kabupaten Lombok Timur. Instrumen pengumpulan data yang digunakan adalah tes pengetahuan kinerja guru, pedoman observasi, wawancara, penilaian portofolio. Pengujian hipotesis dilakukan dengan melihat peningkatan kinerja guru persiklus. Rata-rata skor tes kinerja meningkat dari 53,2 hingga mencapai 68,9 pada siklus II. Karena skor kinerja telah mencapai 68,9 (dibulatkan menjadi 70 ), maka Hipotesis alternatif (Ha) yang menyatakan pelaksanaan MGMP di SMPN 1 Labuhan Haji dapat meningkatkan kinerja guru dalam merencanakan pembelajaran, menerapkan strategi pembelajaran, pengelolaan kelas, dan mengevaluasi pembelajaran diterima. Hasil penelitian ini adalah bahwa pelaksanaan MGMP di SMP N 1 Labuhan Haji dapat meningkatkan kinerja guru Bahasa Indonesia dalam merencanakan pembelajaran, menerapkan strategi pembelajaran, mengelola kelas dan mengevaluasi pembelajaran. Dengan demikian pelaksanaan MGMP yang dilaksanakan berdasarkan prinsip-prinsip manajemen sumberdaya manusia dapat meningkatkan kinerja guru Bahasa Indonesia dalam pembelajaran. Oleh karena itu, disarankan pada guru, kepala sekolah, dan pengawas pendidikan agar memberdayakan MGMP MGMP yang ada terutama di sekolah karena dapat meningkatkan profesionalisme guru.
\end{abstract}

Kata kunci: kinerja guru; MGMP; bahasa Indonesia. 


\section{PENDAHULUAN}

Profesi guru dewasa ini sedang menjadi pusat perhatian, baik di kalangan pakar pendidikan maupun masyarakat umum. Bahkan tahun-tahun ini terakhir guru menjadi pusat perhatian dengan sertifikasinya. Banyak kalangan yang berharap terhadap program ini demi peningkatan profesionalisme guru. Di lain pihak memandang dengan cemburu bahwa sertfikasi adalah upaya yang semata-mata bertujuan untuk menaikkan tunjangan guru, tanpa berpengaruh terhadap kompetensinya dengan menyodorkan bukti berupa penelitian ilmiah.

Banyak pandangan-pandangan yang berkaitan dengan prilaku guru, termasuk ancaman pelanggaran HAM bagi guru yang melakukan tindak kekerasan terhadap siswa. Sekecil apa pun kesalahan yang diperbuat guru mengundang reaksi dari masyarakat. Hal ini tentu dapat dimaklumi karena guru adalah panutan masyarakat (public figure).yang sedang naik daun.

Lebih dari sekedar panutan, guru sampai kapan pun tetap eksis, posisi guru di depan kelas sulit digantikan walaupun oleh mesin canggih, karena tugasnya menyangkut pembinaan sikap, mental dan karakter peserta didik yang memiliki aspek manusiawi yang unik, berbeda satu sama lain. Hal inilah yang memerlukan pendekatan manusiawi yang tentu hanya bisa dilakukan oleh manusia terdidik ( Guru professional).

Guru merupakan jabatan atau profesi yang memerlukan keahlian khusus, untuk menjadi guru di perlukan syarat-syarat khusus, apalagi sebagai guru yang professional yang menguasai betul seluk beluk pendidikan dan pengajaran dan berbagai ilmu pengetahuan lainnya. (Usman, 2002 : 13 ) Lebih jelas ditegaskan dalam Undang-undang Republik Indonesia No. 14 tentang guru dan dosen, pasal 8 berbunyi guru wajib memiliki kualifikasi akademik, kompetensi, sertifikat pendidik, sehat jasmani dan rohani, serta memiliki kemampuan dalam mewujudkan pendidikan nasional. Dipertajam dalam pasal 10, kompetensi yang harus dimiliki oleh seorang guru meliputi kompetensi pedagogik, kompetensi kepribadian, kompetensi sosial, dan kompetensi professional

Secara khusus Mulyasa ( 2004) menggarisbawahi keberhasilan pendidikan sangat ditentukan oleh keberhasilan mengelola tenaga kependidikan ( personalia pendidikan ). Peningkatan produktivitas dan prestasi pendidikan dapat dilakukan dengan meningkatkan prilaku mereka melalui aplikasi berbagai konsep dan teknik manajemen personalia modern. Manajemen tersebut selanjutnya diarahkan untuk mendayakan mereka secara efektif dan efisien untuk mencapai hasil yang optimal, sesuai dengan meningkatkan prilaku. Mereka secara efektif dan efisien untuk mencapai hasil yang optimal, sesuai dengan masyarakat.

Berbicara tentang manajemen personalia guru, kegiatan program peningkatan mutu guru sangat perlu dilakukan secara terprogram, kontinyu, dan sesuai dengan kondisi serta kemampuan para guru saat ini. Bentuk peningkatan mutu guru ini sudah dijalankan dengan baik sehingga menghasilkan guru-guru yang berkinerja tinggi. Menurut H.Wang, dkk ( dalam Samani, 2006 ) Negara-negara seperti Australia, Inggris, Hongkong, Jepang, Korea Selatan, Belanda, Singapura, dan Amerika Serikat memiliki kinerja guru cukup yang baik karena kedelapan negara tersebut melakukan penyaringan calon guru, sejak mulai masuk perguruan tinggi, sampai pembinaan yang diikutinya ketika sudah berprofesi menjadi guru. Temuan ini sangat menarik dan layak diperhatikan oleh siapa saja yang berkepentingan dengan upaya peningkatan guru. 
Dalam pengembangan tenaga guru terdapat 2 model pengembangan, yaitu pengembangan secara formal dan secara informal. Pengembangan secara informal yaitu guru atas keinginan sendiri melatih dan mengembangkan dirinya dengan mempelajari buku-buku literatur yang ada hubungannya dengan pekerjaan atau jabatan. Pengembangan secara informal menunjukkan bahwa guru tersebut berkeinginan keras untuk maju dengan cara meningkatkan kinerjanya. Sedangkan pengembangan secara formal adalah guru ditugaskan lembaga pendidikan untuk mengikuti pendidikan atau pelatihan baik yang dilakukan oleh organisasi maupun yang dilaksanakan oleh lembaga pendidikan atau lembaga pelatihan.

Di samping penataran dan pelatihan ada juga wadah yang lain untuk mengembangkan kinerja guru. Mondy dan Premeaux (2002) "Performance is a form of work or business as result of physical appearance or idea. Performance is often also associated with competence in self-offenders. Kinerja adalah suatu bentuk hasil kerja atau hasil usaha berupa tampilan fisik maupun gagasan. Kinerja sering juga dihubungkan dengan kompetensi pada diri pelakunya. Lebih lanjut, Brown ( 1999 ) menyatakan "Performance is the result or the overall success rate of a person during a certain period in carrying out the task as compared to the range of possibilities, such as with the standards work, the target or targets and criteria that have been determined in advance and agreed. Kinerja adalah hasil atau tingkat keberhasilan seseorang secara keseluruhan selama periode tertentu di dalam melaksanakan tugas dibandingkan dengan beberapa kemungkinan, misalnya standar hasil kerja, target atau sasaran serta criteria yang telah ditentukan dan disepakati bersama.

Sementara itu, Bowin dan Harvey ( 1996 ) menyatakan bahwa "Performance may be defined as the accomplishment of an employes or manager assigned duties and the outcomes produced on a job fungtion or activity during specied time period." Kinerja adalah catatan hasil yang diproduksi pada fungsi pekerjaan tertentu atau kegiatan selama periode waktu tertentu. Inti dari beragam pendapat tersebut, kinerja adalah hasil kerja atau prestasi kerja seseorang secara keseluruhan selama periode tertentu dalam melaksanakan pekerjaannya. Kinerja guru adalah kemampuan guru dalam mengelola kegiatan belajar mengajar di kelas secara efektif dan efisien untuk mencapai tujuan pembelajaran. Indikator-indikator kinerja guru itu adalah kemampuan merencanakan pembelajaran, menerapkan strategi pembelajaran, mengelola kelas, dan kemampuan mengevaluasi pembelajaran.

Salah satu wadah untuk mengembangkan kinerja guru yaitu forum komunikasi seperti KKG, MKKS, dan MGMP sangat cocok untuk mengembangkan kinerja guru dalam konteks otonomi pendidikan terutama Manajemen Berbasis Sekolah (MBS). KKG (Kelompok Kerja Guru ), MGMP ( Musyawarah Guru Mata Pelajaran ), MKKS ( Musyawarah Kepala-Kepala Sekolah) adalah wadah pertemuan guru sebagai sarana komunikasi, konsultasi, dan tukar pengalaman untuk meningkatkan profesionalisme guru. Pendidikan dan pelatihan tidak hanya dilakukan oleh dinas pendidikan kabupaten/kota atau propinsi, sekolah pun bisa menyelenggarakan sendiri sesuai dengan situasi, kebutuhan dan kemampuan guru di sekolah (Mulyasa, 2004).

Musyawarah Guru Mata Pelajaran ( MGMP) adalah wadah kegiatan profesional untuk membina hubungan kerja sama secara koordinatif dan fungsional antara sesama guru mata pelajaran yang bertugas pada SMP dan SMA. Tugas dan tanggung jawab MGMP adalah merencanakan, melaksanakan, dan mengevaluasi serta melaporkan hasil kegiatan bahkan menentukan bentuk tindak lanjut. Kegiatan pokok MGMP adalah kegiatan bidang kurikulum, perencanaan pembelajaran, strategi dan media pembelajaran, evaluasi pembelajaran, pembuatan bahan ajar, LKS, problematika 
pembelajaran dan siswa, dan paradigm perkembangan pendidikan dan peraturan perundangundangan bidang pendidikan (Depdikbud, 2005 )

Selama 10 tahun peneliti pelaksanakan MGMP di SMP kabupaten Lombok Timur kurang memenuhi harapan kita semua. Perencanaannya sering terkesan hanya untuk menyiasati agar dana proyek dapat direalisasikan, sehingga persiapan kurang matang, pelaksannaannya penuh dengan komentar-komentar yang kurang memuaskan dari para peserta. Motivasi peserta datang ke MGMP hanya menuruti perintah dari atasan, atau sekedar ingin ketemu dengan teman lama, bahkan boleh jadi cara untuk mencari belanja tambahan. Padahal idealnya MGMP dapat memberikan pengetahuan dan keterampilan baru. Pada dasarnya semua peserta butuh informasi, sehingga acara bagi-bagi, dan tukar menukar bentuk perangkat pembelajaran, mulai dari RPP, silabus, LKS, Bahan Ajar, soal-soal ulangan dan lain-lain. Di era komputerisasi yang canggih sekarang ini, peserta hanya tinggal pesan, sebentar saja sudah ada di Laptop, bahkan di sakunya ( handphonenya).

Keadaan ini mengakibatkan hakikat dan tujuan MGMP untuk meningkatkan kinerja guru tidak pernah terwujud, karena prinsip-prinsip pelaksanaan MGMP yang sebenarnya tidak pernah terlaksana. Singkatnya MGMP belum dikelola dengan maksimal, komponen-komponen yang ada di dalamnya tidak difungsikan secara optimal.

Revitalisasi MGMP sangat diperlukan yaitu perberdayaan unsur dan prinsip-prinsip penting dalam MGMP, agar pelaksanaannya efektif dan efisien untuk mencapai tujuan yang optimal, yaitu meningkatkan kinerja guru atau kompetensi profesionalnya.

Pergantian otonomi pendidikan seiring dengan perubahan paradigma proses pembelajaran dari teaching menjadi learning, memerlukan proses pembelajaran, baik menyangkut perencanaan, pelaksanaan, maupun evaluasi. Hal ini menuntut reorientasi penyelenggaraan MGMP baik dari tujuan penyelenggaraan, jadwal pertemuan, maupun materi, sehingga bermanfaat secara optimal ( Mulyasa, 2004)

Penelitian ini mencoba untuk mengefektifkan pelaksanaan MGMP dengan memperhatikan konsep manajemen diklat, diharapkan para guru MGMP Bahasa Indonesia di SMPN 1 Labuhan haji dapat mencari solusi kesulitan dan permasalahan guru dalam pembelajaran dan pendidikan di sekolah, sehingga dapat meningkatkan kinerjanya serta mutu pendidikan di sekolah.

\section{METODE PENELITIAN}

Penelitian ini merupakan penelitian tindakan kelas ( Classroom Action Research). Penelitian Tindakan Kelas ( PTK) adalah suatu bentuk penelitian yang bersifat reflektif dengan melakukan tindakan tertentu untuk memperbaiki dan meningkatkan kinerja kelas agar lebih berkualitas, sehingga siswa dapat memperoleh hasil belajar yang lebih baik ( Asrori, 2008:6).

Penelitian ini mencoba menerapkan konsep-konsep manajemen dalam pelaksanaan MGMP bahasa dan sastra Indonesia untuk meningkatkan kinerja guru Bahasa Indonesia di Kecamatan Selong. Objek penelitian ini adalah guru-guru Bahasa dan Sastra Indonesia yang terhimpun dalam forum Komunikasi MGMP rayon tengah yang berpusat di SMPN 1 Labuhan Haji. Penelitian ini bertujuan 1) meningkatkan kinerja guru Bahasa Indonesia dalam merencanakan pembelajaran melalui pelaksanaan MGMP di SMPN 1 Labuhan Haji 2) meningkatkan kinerja guru Bahasa Indonesia dalam menerapkan strategi pembelajaran melalui pelaksanaan MGMP di SMPN 1 
Labuhan Haji. 3) meningkatkan kinerja guru Bahasa Indonesia dalam pengelolaan kelas melalui pelaksanaan MGMP di SMPN 1 Labuhan Haji 4) dan meningkatkan kinerja guru Bahasa Indonesia dalam mengevaluasi pembelajaran melalui pelaksanaan MGMP di SMPN 1 Labuhan Haji.

Penelitian tindakan ini direncanakan dalam 3 siklus, dan tiap siklus akan dilakukan 4 tahapan, yaitu perencanaan, pelaksanaan, observasi \& evaluasi, refleksi \& revisi. Sebelum siklus pertama dilakukan didahului dengan studi awal, untuk lebih jelasnya diterangkan dalam disain penelitian.

STUDI AWAL-- PERENCANAAN - PELAKSANAAN EVALUASI \& OBSERVASI- REFLEKSI \& REVISI

( SIKLUS I/ MGMP PUTARAN I)

PERENCANAAN - PELAKSANAAN--EVALUASI \& OBSERVASI-- REFLEKSI \& REVISI

( SIKLUS II/ MGMP PUTARAN II)

PERENCANAAN_PELAKSANAAN--EVALUASI \& OBSERVASI-- REFLEKSI \& REVISI

(SIKLUS III/ MGMP PUTARAN III)

Data yang dikumpulkan dalam penelitian ini terdiri atas data studi awal berupa masalah yang dihadapi oleh guru-guru anggota MGMP Bahasa Indonesia di sekolah masing-masing, metode pengumpulanya adalah metode wawancara, data berupa permasalahan perencanaan, pelaksanaan, dan evaluasi pembelajaran yang diperoleh dalam studi awal, dijadikan dasar untuk mendiagnosis permasalahan pembelajaran yang dihadapi oleh guru anggota MGMP di lapangan, sehingga dapat direncanakan tindakan yang tepat.

Data kinerja guru diperoleh dengan 3 instrumen, yaitu 1) tes pengetahuan yang terdiri atas pengetahuan merencanakan pembelajaran, melaksanakan strategi pembelajaran, 2) Kemampuan praktek mengajar langsung di kelas diperoleh dengan instrument pedoman observasi, yang berisi aspek cara menyampaikan materi, cara memberi contoh ( modeling), mengaktifkan siswa, memberi penguatan, mengatur waktu, mengorganisir siswa, mengatur dan memanfaatkan fasilitas belajar. dan 3) Penilaian Portofolio yang dihasilkan oleh para guru anggota MGMP, berupa RPP, Pemetaan Materi esensial, dan format penetapan KKM ( Kriteria Ketuntasan Minimal ). Proses pelaksanaan MGMP diamati menggunakan pedoman observasi.

Analisis data dalam penelitian tindakan ini adalah membandingkan rerata tes kinerja guru Bahasa Indonesia sesudah dilaksanakan MGMP putaran I, II, ( Siklus I, II, ). Indikator untuk keberhasilan MGMP ini dalam meningkatkan kinerja adalah keberhasilan guru-guru dalam mencapai rerata tes yaitu 70 .

\section{HASIL DAN PEMBAHASAN}

\section{Hasil Penelitian}

Sebelum dilakukan tindakan terlebih dahulu diadakan penelitian awal yaitu pada tanggal 7 s.d 8 Januari 2016. Penelitian awal yang dilakukan bertujuan untuk memperoleh masukan tentang permasalahan guru di lapangan, sehingga terdapat bahan yang lengkap untuk pelaksanaan MGMP ( Tindakan). Hasil Penelitian / Studi Awal, setelah dilakukan wawancara dengan para guru anggota MGMP Bahasa Indonesia rayon tengah, diperoleh data tentang permasalahan esensial yang dihadapi, dari sejumlah hasil wawancara masalah-masalah yang disimpulkan meliputi, masalah pengembangan silabus, dan RPP, penerapan strategi pembelajaran, penyesuaian metode dan materi pembelajaran, serta bagaimana membuat soal yang standard dan valid. 


\subsection{Hasil Penelitian Pada Siklus I}

Sesuai dengan hasil wawancara terhadap guru-guru anggota MGMP, maka diadakan perencanan untuk tindakan siklus I yaitu MGMP putaran pertama yang diadakan 9 januari 2017. Dalam perencanaan ini peneliti sekaligus sebagai ketua MGMP mengundang pengurus MGMP dan beberapa perwakilan untuk menentukan waktu, tempat, materi dan instruktur yang berkompeten. Materinya adalah pengembangan silabus, pembuatan RPP, Pelaksanaan praktek mengajar ( feerteaching ), pembuatan soal-soal terstandar, dan cara penilaian sikap dan keterampilan. Instruktur adalah guru-guru yang sudah memperoleh SK sebagai instruktur nasional dan pengawas bidang studi bahasa Indonesia. Panitia terdiri atas Ketua, Sekretaris, dan bendahara, serta dibantu oleh perlengkapan dan akomodasi. MGMP putaran I ( siklus I) diadakan bertempat di SMPN 1 Labuhan Haji.

Sesuai dengan jadual yang sudah disusun oleh panitia, MGMP dapat terlaksana dengan baik dari tanggal 11 s.d 17 Januari 2016, pada hari pertama masih ada 2 guru yang terlambat, tapi tidak mengganggu kegiatan secara umum, Sebagian besar peserta sangat tertarik mengajukan pertanyaan yang beragam terutama tentang RPP, Pembelajaran berbasis teks, Saintifiks learning, dan Penilaian sikap dalam pembelajaran. Keterlibatan dan keaktifan para guru dalam kelas di tunjukkan dengan semangat mereka membedah standar isi kurikulum dan silabus kurikulum 2013. Setelah melakukan diskusi kelompok kecil pada hari ke 3, maka pada hari keempat dilanjutkan dengan latihan membuat bahan ajar dan RPP, hari ke 5 dilanjutkan dengan presentase RPP dan bahan ajar. Pada hari ke-6 diadakan simulasi mengajar (feerteaching ).Pada hari ke-7 digelar refleksi, dan pada akhir pertemuan diadakan tes kinerja tertulis, adapun hasil tes dapat dilihat pada tabel berikut :

Tabel 1.2 skor kinerja guru Bahasa Indonesia pada siklus I

\begin{tabular}{|c|c|c|c|c|c|c|}
\hline \multirow[b]{2}{*}{$\mathrm{NO}$} & \multirow[b]{2}{*}{ GURU } & \multicolumn{4}{|c|}{ SKOR TES } & \multirow[t]{2}{*}{ TOTAI } \\
\hline & & 1 & 2 & 3 & 4 & \\
\hline 1 & Gr. 1 & 7 & 9 & 7 & 8 & 31 \\
\hline 2 & Gr.2 & 6 & 8 & 9 & 7 & 30 \\
\hline 3 & Gr.3 & 9 & 9 & 7 & 7 & 32 \\
\hline 4 & Gr.4 & 8 & 8 & 7 & 9 & 32 \\
\hline 5 & Gr.5 & 7 & 5 & 6 & 7 & 25 \\
\hline 6 & Gr.6 & 5 & 9 & 6 & 9 & 29 \\
\hline 7 & Gr.7 & 8 & 10 & 8 & 6 & 32 \\
\hline 8 & Gr.8 & 6 & 6 & 6 & 5 & 23 \\
\hline 9 & Gr.9 & 7 & 7 & 8 & 8 & 30 \\
\hline 10 & Gr.10 & 6 & 6 & 7 & 9 & 28 \\
\hline 11 & Gr.11 & 5 & 6 & 7 & 9 & 27 \\
\hline 12 & Gr.12 & 6 & 5 & 6 & 5 & 22 \\
\hline 13 & Gr.13 & 5 & 2 & 5 & 7 & 19 \\
\hline 14 & Gr.14 & 8 & 5 & 8 & 3 & 24 \\
\hline \multirow[t]{3}{*}{15} & Gr.15 & 4 & 5 & 6 & 7 & 22 \\
\hline & TOTAL & 97 & 100 & 103 & 106 & 406 \\
\hline & Rata-rata & 6.5 & 6,7 & 6,9 & 7,1 & 27,1 \\
\hline
\end{tabular}

Keterangan : 1.perencanaan pembelajaran, 3. Pengelolaan kelas
2.Strategi pembelajaran
4. Evaluasi pembelajaran 
Kegiatan MGMP ini diadakan dengan teknik in service training dan on service learning. In service training adalah kegiatan pada saat di kelas untuk menerima materi pelatihan dari tanggal 11 s.d 17 Januari 2016. On service learning adalah kegiatan pendampingan langsung di sekolah tempat tugas guru anggota MGMP. Kegiatan dilakukan selama 1 bulan pada 7 SMP, yaitu SMPN 1 , SMPN 2 , SMPN 3 , SMPN 4, dan SMPN 5 Selong, SMPN 1, SMPN 2 Labuhan Haji. Pada kegiatan ini peneliti dibantu oleh Instruktur sekaligus sekretaris MGMP mengobservasi guru-guru mengajar ( real teaching ) di sekolahnya sesuai dengan jadual yang ditetapkan. Adapun hasil observasi terhadap kemampuan mengelola kelas setelah MGMP putaran I (Siklus I) ketika guru mengadakan pembelajaran di sekolah tempat bertugas, dapat dilihat pada tabel berikut :

Tabel 1.2 skor kinerja guru Bahasa Indonesia pada siklus I

\begin{tabular}{|l|l|l|l|l|l|l|l|l|l|}
\hline & & \multicolumn{7}{|c|}{ SKOR observasi } & \multirow{2}{*}{ TOTAL } \\
\cline { 3 - 11 } NO & GURU & 1 & 2 & 3 & 4 & 5 & 6 & 7 & \\
\hline 1 & Gr. 1 & 3 & 3 & 4 & 3 & 2 & 2 & 3 & 20 \\
\hline 2 & Gr.2 & 3 & 3 & 3 & 4 & 2 & 3 & 3 & 21 \\
\hline 3 & Gr.3 & 2 & 3 & 4 & 2 & 3 & 3 & 3 & 20 \\
\hline 4 & Gr.4 & 2 & 3 & 4 & 3 & 2 & 3 & 3 & 20 \\
\hline 5 & Gr.5 & 2 & 4 & 3 & 2 & 3 & 2 & 3 & 19 \\
\hline 6 & Gr.6 & 3 & 4 & 3 & 3 & 3 & 4 & 3 & 23 \\
\hline 7 & Gr.7 & 2 & 3 & 3 & 3 & 3 & 3 & 3 & 20 \\
\hline 8 & Gr.8 & 3 & 3 & 3 & 4 & 2 & 2 & 3 & 20 \\
\hline 9 & Gr.9 & 2 & 2 & 2 & 2 & 2 & 3 & 2 & 15 \\
\hline 10 & Gr.10 & 1 & 2 & 2 & 3 & 3 & 3 & 2 & 16 \\
\hline 11 & Gr.11 & 3 & 2 & 1 & 4 & 2 & 2 & 3 & 17 \\
\hline 12 & Gr.12 & 2 & 1 & 4 & 3 & 1 & 2 & 2 & 15 \\
\hline 13 & Gr.13 & 1 & 3 & 3 & 2 & 3 & 2 & 2 & 16 \\
\hline 14 & Gr.14 & 3 & 2 & 2 & 1 & 2 & 2 & 2 & 14 \\
\hline 15 & Gr.15 & 2 & 2 & 3 & 3 & 2 & 2 & 2 & 16. \\
\hline & TOTAL & 34 & 40 & 44 & 42 & 35 & 38 & 39 & 272 \\
\cline { 2 - 8 } & Rata- & 23 & 27 & 29 & 28 & 23 & 25 & 26 & 18,1 \\
\hline & rata & & & & & & & & \\
\hline
\end{tabular}

Keterangan :

1. Menyampaikan bahan

2. memberi contoh

3. memberikan kesempatan pada murid aktif

4. memberi penguatan

5. mengatur penggunaan waktu

6. mengorganisir murid

7. mengatur dan memanfaatkan fasilitas belajar.

Pada akhir siklus I ( Putaran MGMP I) peserta mengumpulkan berkas-berkas berupa bahan penilaian fortopolio. Hasil pengamatan terhadap fortopolio guru-guru anggota MGMP yang berupa RPP, KKM, dan Pemetaan materi esensial adalah sebagai berikut. 


\begin{tabular}{|c|c|c|c|c|c|}
\hline \multirow[t]{2}{*}{$\mathrm{NO}$} & \multirow[t]{2}{*}{ GURU } & \multicolumn{3}{|c|}{$\begin{array}{c}\text { SKOR } \\
\text { FORTOFOLIO }\end{array}$} & \multirow[t]{2}{*}{ TOTAL } \\
\hline & & 1 & 2 & 3 & \\
\hline 1 & Gr. 1 & 5 & 5 & 5 & 15 \\
\hline 2 & Gr. 2 & 5 & 5 & 5 & 15 \\
\hline 3 & Gr. 3 & 5 & 5 & 5 & 15 \\
\hline 4 & Gr.4 & 5 & 0 & 0 & 5 \\
\hline 5 & Gr.5 & 5 & 5 & 5 & 15 \\
\hline 6 & Gr.6 & 5 & 5 & 5 & 15 \\
\hline 7 & Gr. 7 & 5 & 5 & 5 & 15 \\
\hline 8 & Gr. 8 & 5 & 0 & 0 & 5 \\
\hline 9 & Gr.9 & 5 & 0 & 0 & 5 \\
\hline 10 & Gr.10 & 5 & 0 & 0 & 5 \\
\hline 11 & Gr.11 & 0 & 0 & 0 & 0 \\
\hline 12 & Gr.12 & 5 & 0 & 0 & 5 \\
\hline 13 & Gr.13 & 0 & 0 & 0 & 0 \\
\hline 14 & Gr.14 & 5 & 0 & 0 & 5 \\
\hline 15 & Gr.15 & 0 & 0 & 0 & 0 \\
\hline \multicolumn{2}{|c|}{ Jumlah } & 60 & 30 & 30 & 120 \\
\hline \multicolumn{2}{|c|}{ Rata-rata } & 4 & 2 & 2 & 8 \\
\hline
\end{tabular}

Keterangan : 1. Rencana Persiapan Pembelajaran (RPP)

2. Pemetaan Materi Pembelajaran

3. Format pemetaan KKM ( Kriteria Ketuntasan Minimal )

\subsection{Hasil penelitian pada Siklus II}

Siklus II ( MGMP putaran II ) dimulai pada tanggal 12 s.d 18 Februari 2016, setelah 2 hari sebelumnya panitia, pengurus MGMP, serta para instruktur mengadakan rapat di SMPN 1 Labuhan Haji.Notulen rapat tertanggal 10 Februari 2016. Rapat perencanaan diadakan mengikuti pola pada rapat perencanaan Siklus I ( MGMP putaran I). Terdapat beberapa hal yang menjadi fokus perhatian yaitu masalah keaktifan peserta terutama pada saat real teaching di sekolah tempat tugas dan fortopolio belum merata.

Dalam pelaksannaan terlihat motivasi peserta meningkat hal ini disebabkan oleh temuantemuan para instruktur saat refleksi, terutama ketidakjelasan pelaksanaan Kurikulum 2013 dalam realteaching, baik tentang saintifiks learning,pembelajaran berbasis teks, penilaian keterampilan dan penilian sikap dalam pembelajaran bahasa Indonesia. Dalam merivisi RPP dan fortopolio motivasi peserta terlihat meningkat, karena memperoleh bentuk format yang sesuai dengan kebutuhan.

Setelah akhir pertemuan diadakan tes kinerja tertulis, adapun hasil tes dapat dilihat pada tabel berikut : 
SeBaSa: Jurnal Pendidikan Bahasa dan Sastra Indonesia

Tabel 1.2 skor kinerja guru Bahasa Indonesia pada siklus II

\begin{tabular}{|c|c|c|c|c|c|c|}
\hline & & \multicolumn{4}{|c|}{ SKOR TES } & \multirow{2}{*}{ TOTAL } \\
\cline { 3 - 6 } NO & GURU & 1 & 2 & 3 & 4 & \\
\hline 1 & Gr. 1 & 7 & 11 & 7 & 9 & 34 \\
\hline 2 & Gr.2 & 12 & 10 & 10 & 11 & 43 \\
\hline 3 & Gr.3 & 10 & 9 & 10 & 9 & 38 \\
\hline 4 & Gr.4 & 8 & 8 & 8 & 10 & 34 \\
\hline 5 & Gr.5 & 7 & 7 & 9 & 9 & 32 \\
\hline 6 & Gr.6 & 7 & 8 & 10 & 9 & 34 \\
\hline 7 & Gr.7 & 10 & 10 & 10 & 10 & 40 \\
\hline 8 & Gr.8 & 8 & 9 & 8 & 9 & 34 \\
\hline 9 & Gr.9 & 7 & 9 & 10 & 11 & 37 \\
\hline 10 & Gr.10 & 7 & 9 & 10 & 10 & 36 \\
\hline 11 & Gr.11 & 7 & 9 & 12 & 11 & 39 \\
\hline 12 & Gr.12 & 9 & 9 & 8 & 7 & 33 \\
\hline 13 & Gr.13 & 10 & 7 & 8 & 11 & 36 \\
\hline 14 & Gr.14 & 10 & 7 & 9 & 10 & 36 \\
\hline 15 & Gr.15 & 9 & 10 & 8 & 9 & 36 \\
\hline & TOTAL & 128 & 132 & 137 & 145 & 542 \\
\cline { 2 - 6 } & Rata-rata & 8,5 & 8,8 & 9,1 & 9,7 & 36,1 \\
\hline
\end{tabular}

Keterangan : 1.perencanaan pembelajaran,

2. Strategi pembelajaran

3. Pengelolaan kelas

4. Evaluasi pembelajaran

Pelaksanaan real teaching dimulai tanggal 22 Februari s.d. 7 maret 2016. Guru dan sekolah yang menjadi sasaran sama dengan siklus I ( MGMP putaran I). Adapun hasil observasi terhadap kemampuan mengelola kelas setelah MGMP putaran I (Siklus I) ketika guru mengadakan pembelajaran di sekolah tempat bertugas, dapat dilihat pada tabel berikut :

Tabel 1.2 skor kinerja guru Bahasa Indonesia pada siklus II

\begin{tabular}{|c|c|c|c|c|c|c|c|c|c|}
\hline \multirow{2}{*}{ NO } & \multirow{9}{*}{ GURU } & \multicolumn{7}{|c|}{ SKOR OBSERVASI } & \multirow{2}{*}{ TOTAL } \\
\cline { 3 - 10 } & & 1 & 2 & 3 & 4 & 5 & 6 & 7 & \\
\hline 1 & Gr. 1 & 3 & 4 & 4 & 3 & 3 & 3 & 4 & 24 \\
\hline 2 & Gr.2 & 4 & 3 & 3 & 3 & 3 & 3 & 3 & 22 \\
\hline 3 & Gr.3 & 3 & 4 & 2 & 4 & 3 & 3 & 2 & 21 \\
\hline 4 & Gr.4 & 3 & 4 & 3 & 3 & 3 & 3 & 4 & 23 \\
\hline 5 & Gr.5 & 2 & 3 & 4 & 3 & 3 & 4 & 3 & 22 \\
\hline 6 & Gr.6 & 4 & 3 & 4 & 3 & 3 & 2 & 3 & 22 \\
\hline 7 & Gr.7 & 3 & 4 & 5 & 3 & 3 & 3 & 3 & 24 \\
\hline 8 & Gr.8 & 3 & 3 & 3 & 3 & 3 & 2 & 3 & 20 \\
\hline 9 & Gr.9 & 3 & 3 & 4 & 2 & 4 & 3 & 3 & 22 \\
\hline 10 & Gr.10 & 2 & 2 & 3 & 3 & 3 & 3 & 2 & 18 \\
\hline 11 & Gr.11 & 3 & 2 & 2 & 3 & 2 & 2 & 3 & 17 \\
\hline 12 & Gr.12 & 2 & 3 & 3 & 3 & 2 & 4 & 3 & 20 \\
\hline
\end{tabular}




\begin{tabular}{|c|c|c|c|c|c|c|c|c|c|}
\hline 13 & Gr.13 & 2 & 2 & 3 & 2 & 3 & 2 & 3 & 17 \\
\hline 14 & Gr.14 & 3 & 2 & 4 & 2 & 2 & 2 & 2 & 17 \\
\hline 15 & Gr.15 & 2 & 3 & 4 & 2 & 2 & 3 & 2 & 18 \\
\hline & TOTAL & 41 & 42 & 51 & 42 & 42 & 42 & 43 & \\
\cline { 2 - 10 } & Rata-rata & 2,7 & 2,8 & & 2,8 & 2,8 & 2,8 & 2,9 & \\
\hline
\end{tabular}

Keterangan : 1. Menyampaikan bahan

2. Memberi contoh

3. Memberikan kesempatan pada murid aktif

4. memberi penguatan

5. mengatur penggunaan waktu

6. mengorganisir murid

7. mengatur dan memanfaatkan fasilitas belajar

\begin{tabular}{|c|c|c|c|c|c|}
\hline \multirow{2}{*}{$\mathrm{NO}$} & \multirow{2}{*}{ GURU } & \multicolumn{3}{|c|}{ SKOR FORTOFOLIO } & \multirow{2}{*}{$\begin{array}{c}\text { TOTA } \\
\text { L }\end{array}$} \\
\hline & & 1 & 2 & 3 & \\
\hline 1 & Gr. 1 & 5 & 5 & 5 & 15 \\
\hline 2 & Gr. 2 & 5 & 5 & 5 & 15 \\
\hline 3 & Gr. 3 & 5 & 5 & 5 & 15 \\
\hline 4 & Gr.4 & 5 & 5 & 0 & 10 \\
\hline 5 & Gr.5 & 5 & 5 & 5 & 15 \\
\hline 6 & Gr.6 & 5 & 5 & 5 & 15 \\
\hline 7 & Gr. 7 & 5 & 5 & 5 & 15 \\
\hline 8 & Gr. 8 & 5 & 0 & 0 & 5 \\
\hline 9 & Gr.9 & 5 & 5 & 5 & 15 \\
\hline 10 & Gr.10 & 5 & 0 & 5 & 10 \\
\hline 11 & Gr.11 & 5 & 5 & 5 & 15 \\
\hline 12 & Gr.12 & 5 & 5 & 5 & 15 \\
\hline 13 & Gr.13 & 5 & 5 & 5 & 15 \\
\hline 14 & Gr.14 & 5 & 5 & 5 & 15 \\
\hline 15 & Gr.15 & 5 & 0 & 0 & 5 \\
\hline \multicolumn{2}{|c|}{ Jumlah } & 60 & 30 & 30 & 165 \\
\hline \multicolumn{2}{|c|}{ Rata-rata } & 4 & 2 & 2 & 13 \\
\hline
\end{tabular}

Ket :1. Rencana Persiapan Pembelajaran ( RPP)

2. Pemetaan Materi Pembelajaran

3. Format Penetapan KKM ( Kriteria Ketuntasan Minimal)

\section{Pembahasanya}

Berdasarkan hasil analisis data dari siklus I s.d. II terdapat skor kinerja guru Bahasa Indonesia yang cukup signifikan, setelah diadakan peningkatan melalui kegiatan MGMP Bahasa Indonesia yaitu 53,2 pada siklus I menjadi 68,9 pada siklus II. 


\begin{tabular}{|l|l|l|l|l|}
\hline \multirow{2}{*}{ SIKLUS } & \multicolumn{3}{|c|}{ Rata-rata skor kinerja } & \multirow{2}{*}{ TOTAL } \\
\cline { 2 - 4 } & 1 & 2 & 3 & \\
\hline PERTAMA & 27,1 & 18,1 & 8,0 & 53,2 \\
\hline SIKLUS & 36,1 & 19,8 & 13,0 & 68,9 \\
\hline
\end{tabular}

Ket. 1. Skor tes kinerja

2. Skor Observasi Pembelajaran

3. Skor portofolio.

Jika melihat tabel di atas, terlihat peningkatan skor kinerja dari siklus I s.d. siklus II, dari 53,2 menjadi 68,9. Sesuai dengan indikator keberhasilan pelaksanaan penelitian ini jika skor kinerja Guru Bahasa Indonesia MGMP belum mencapai 70, maka perlu dikembangkan melalui MGMP sampai tiga putaran atau siklus, tetapi pada siklus II ( MGMP putaran II) skor kinerja telah mencapai standar yang ditetapkan yaitu 70 (pembulatan dari 68,9), maka tidak perlu diadakan siklus III ( MGMP putaran III).

Berdasarkan uraian di atas dapat disimpulkan bahwa penelitian tindakan ini membuktikan adanya peningkatan kinerja guru Bahasa Indonesia setelah mereka mengikuti kegiatan MGMP di SMPN 1 Labuhan Haji Lombok Timur. Dengan demikian hipotesis alternatif ( $\mathrm{Ha}$ ) yang menyatakan pelaksanaan MGMP di SMPN 1 Labuhan Haji dapat meningkatkan kinerja guru Bahasa Indonesia dalam merencanakan pembelajaran, menerapkan strategi pembelajaran, pengelolaan kelas, dan evaluasi pembelajaran diterima.

Peningkatan kinerja dengan pelaksanaan MGMP ini, disebabkan karena peserta melakukan kegiatan dengan baik. Peserta memiliki motivasi yang tinggi karena materi yang mereka terima sesuai dengan kebutuhan nyata di sekolah.Peranan studi awal dalam perencanaan MGMP sangat dibuthkan dalam prencanaan materi, metode, dan instruktur dalam pelaksanaan MGMP. Pelaksanaan yang efektif dan efisien ditunjukkan dengan konsistennya peserta dalam menaati jadual yang sudah ditetapkan. Termasuk tahap evaluasi dan observasi di sekolah, semuanya terselenggara dengan baik karena antara MGMP dan sekolah serta pihak dinas pendidikan sudah tercipta komunikasi yang baik. Beberapa MOU sudah disepakati.

Hal ini memperkuat beberapa pendapat dan temuan-temuan sebelumnya dalam penelitian tentang MGMP, salah satu dari beberapa pendapat itu adalah bahwa kegiatan MGMP yang dilakukan dengan intensif dapat dijadikan sebagai wahana pengembangan diri guru mata pelajaran untuk meningkatkan kapasitas dan kemampuannya, serta menambah pengetahuan dan keterampilan masing-masing. Dengan mengefektifkan MGMP semua kesulitan dan permasalahan yang dihadapi oleh guru dalam kegiatan pembelajaran di sekolah dapat diatasi atau dicari solusinya, serta dapat meningkatkan mutu pendidikan di sekolah.

\section{SIMPULAN}

Berdasarkan permasalahan, deskripsi data, analisis data dan pembahasan pada pemaparan sebelumnya, dapat disimpulkan bahwa pelaksanaan MGMP di SMPN 1 Labuhan Haji dapat meningkatkan kinerja guru Bahasa Indonesia dalam merencanakan pembelajaran, menerapkan strategi pembelajaran, mengelola kelas pembelajaran, dan mengevaluasi pembelajaran. Dengan 
demikian pelaksanaan MGMP yang dilaksanakan berdasarkan prinsip-prinsip manajemen sumberdaya manusia dapat meningkatkan kinerja guru Bahasa Indonesia dalam pembelajaran. Oleh karena itu, disarankan pada guru, kepala sekolah, dan pengawas pendidikan agar memberdayakan MGMP MGMP yang ada terutama di sekolah karena dapat meningkatkan profesionalisme guru.

\section{Saran-saran}

Berdasarkan simpulan di atas, maka diperlukan tindak lanjut, oleh sebab itu ada beberapa saran saran pada pihak-pihak sbb.:

1. Guru, pada umumnya dan guru Bahasa Indonesia pada khususnya, agar terus meningkatkan mutu, mengefektifkan, mengaktifkan pelaksanaan MGMP di kecamatan atau di sekolah, agar dapat meningkatkan kinerja dan profesionalisme sebagai seorang guru.

2. Kepala sekolah dan madrasah perlu mendukung, mengarahkan, dan memberikan kesempatan kepada tenaga pendidikan di sekolah untuk mengadakan, mengikuti, serta meningkatkanmutu pelaksanaan MGMP, karena hal ini adalah wujud penerapan MBS (Manajemen Berbasis Sekolah) yang nyata untuk mengembangkan kinerja tenaga kependidikan terutama guru.

3. Dinas pendidikan dan kebudayaan, baik di kabupaten maupun kecamatan melalui pengawas pendidikan sebagai perpanjangan tangannya, mendukung sepenuhnya keberadaan MGMP di tempat tugas masing-masing. Bentuk dukungan ini adalah berupa bimbingan baik materi, dan nara sumber maupun sistem manajemen. Pengawas sebagai atasan para guru hendaknya menjadi mentor dan mitra kerja yang baik, bagi guru-guru anggota MGMP, secara berkelanjutan perlu diterapkan sistem monev yang standar, agar kontribusinya nyata dan terukur bagi seorang guru.

\section{DAFTAR PUSTAKA}

Abu-Duhou. I. 2002. Schoool Based Management ( Manajemen Berbasis Sekolah ). Jakarta:Logos wacana ilmu.

Achsanuddin.2008. MGMP dan Profesionalisme Guru. Mataram: IAIN Mataram.

Aqib. Z. 2002. Profesionalisme Guru Dalam Pembelajaran, Surabaya: Insan.

Depdikbud, 2005. Pedoman Musyawarah Guru Mata Pelajaran pada SLTP dan SLTA. Jakarta : Dirjen Dikdasmen.

Fathoni, A. 2008. Manajemen Sumber Daya Manusia.Bandung: Mizan.

Hadiprayitno. G. 2008. Guru Profesional : Antara Harapan dan Kenyataan, makalah disampaikan pada Seminar Guru Profesional di Mataram, 13 April 2008.

Joni, T. R. 2009. Peningkatan Mutu Pendidikan Dasar dan Menengah Melalui Strategi Aktif dan Pembinaan Profesional Guru, Kepal Sekolah, Penilik dan Pengawas Sekolah, Jakarta :Depdikbud.

Suyanto, 2009. Peningkatan Kompetensi Pendidik dan Tenaga Kependidikan melalui pemberdayaan MGMP/KKG,KKS,MKKS, dan MKPS. Artikel Buletin Kita : LPMP NTB, Edisi 01/tahun.1/XI/2009. 